\title{
Attachment Hypothesis of REM Sleep \\ Toward an Integration of Psychoanalysis, Neuroscience, and Evolutionary Psychology and the Implications for Psychopathology Research
}

\author{
Michael J. Zborowski, PhD, and Patrick McNamara, PhD \\ State University of New York College at Buffalo
}

In this article the authors propose, on the basis of a review of the evolutionary and neuropsychological study of REM sleep, that REM sleep functions to promote attachment and that in the mature state it may promote sexual pair bonding and serve related compensatory functions. The attachment hypothesis is consistent with known psychobiologic correlates of REM sleep, with classical psychoanalytic theory regarding dreams, and with evidence from research on attachment. The authors argue that this hypothesis leads to a new understanding of the role of repression and the dream work, and has broad implications for psychopathology research. They argue that although many in the cognitive and neural sciences have largely dismissed S. Freud's (1900/1953) theorizing on dreams, there is important complementarity when it is evaluated through the lens of the attachment hypothesis.

\footnotetext{
Michael J. Zborowski, PhD, and Patrick McNamara, PhD, Department of Psychology, State University of New York College at Buffalo.

We thank Robert Bornstein and Howard Reid for their helpful comments and suggestions regarding this article.

For the reader desiring more thorough coverage of the psychobiology of REM sleep as it relates to the theory outlined herein, see McNamara (1996). Order of authorship was arbitrarily determined, owing to the relative equivalence of contribution.

Correspondence concerning this article should be addressed to Michael J. Zborowski, PhD, Department of Psychology, State University of New York College at Buffalo, 1300 Elmwood Avenue, Buffalo, New York 14222-1095. Electronic mail may be sent via Internet to zborowmj@buffalostate.edu.
} 
Modern work on dreams in the neural and cognitive sciences has largely been dismissive of classical psychoanalytic approaches to the meaning and function of dreams. One of the authors (Hobson, 1988) of the often cited activationsynthesis hypothesis on dream formation asserted that dreams, contrary to what Freud (1900/1953) argued, have no disguised meaning at all. Rather, Hobson argued that dreams represent an attempt on the part of the cortex to "synthesize" or to interpret random activation patterns generated in subcortical centers. Dream content reflects these synthesizing efforts of the forebrain and, thus, dream content directly represents the dreamer's drives, fears, and associations. Hobson derided the psychoanalytic theory of the dream as unscientific because (a) it is not empirically based and (b) it is not framed in such a way as to make it amenable to direct experimental test. When viewed through the lens of the attachment hypothesis as outlined below, however, we would suggest that Freud's work is consistent with the data of the modern neuroscientific study of REM sleep. We review below some of the empirical evidence for the attachment hypothesis and provide detailed suggestions for experimental tests of the hypothesis. The theory also makes explicit predictions regarding the role of REM in fostering adaptation, and in the onset and course of certain forms of psychopathology.

For Nobel Prize winner Francis Crick and his associate Graeme Mitchison (Crick \& Mitchison, 1986), dreams are meaningless. REM sleep functions in order to reduce fantasy and the interaction of related ideas and concepts in memory. REM sleep, loosely speaking, is a form of reverse learning. The cognitive system is purged of elements that might interfere with efficient functioning. It therefore might even be harmful to remember dreams. With regard to Freud's work, Crick and Mitchison (1986) had this to say:

There seems little point in dwelling on Freud's ideas since they hardly fit the biological data. Freudians have no unforced explanation for the large amount of REM in the unborn and the newly born and the occurrence of REM in so many different species of mammals and birds. To a modern neuroscientist Freud's theories, in spite of their appeal to the contemporary imagination, seem little better than the common belief in earlier times that dreams foretold the future, a belief which also held strong intuitive appeal (p. 245)

We hope to show below that Freud's core theory of the dream-that the latent content represented a revival of infantile libidinal strivings-is consistent with modern neurobiological descriptions of REM sleep.

For Foulkes (1985), the most prominent cognitive psychologist who has specialized in the study of dreams, "there is no more underlying meaning in dreaming than there are angels who might sit on the heads of pins" (p. 191). In his review of Freud's (1900/1953) work, Foulkes (1978) argued for a distinction between Freud's topographic model (e.g., unconscious, preconscious, 
conscious) of the dream experience, which Foulkes believed was derived from the data-based free-association method, and the economic model of the dreaming mind, which constituted Freud's theory of the dream: "The wishfulfilment hypothesis, the notion that repressed infantile sexual wishes instigate dreams, and the energetic characterizations of 'primary' and 'secondary' processes are not generated by, but are forced upon, the data in the free association matrix" (Foulkes, 1978, p. 86). Thus, Foulkes rejected the wishfulfillment hypothesis and the associated ideas concerning the regressive and libidinal nature of the dream.

Alongside this anti-Freudian "eliminatavist" trend in modern cognitive neuroscience, a second "revisionist" trend has developed that finds some merit in Freud's (1900/1953) theory of dreams but disputes some of his conclusions. Winson (1985), for example, argued that dreaming represents a form of "off-line" or unconscious memory processing. Basic behavioral strategies important for survival are acquired during a critical period in early development. REM sleep, according to Winson, somehow constructs or rehearses these basic strategies of behaviors. According to Winson, these basic behavioral orientations constitute the unconscious. Winson, however, placed the emphasis on cognitive and memory processing and had little to say about the infantile and libidinal nature of the dream. If we include attachment, compensatory, and reproductive strategies in the repertoire of basic behavioral strategies that are rehearsed during REM, then Winson's ideas may be close to our own.

Van de Castle (1994) found dreams to be an abundant source of meanings for the dreamer but yet found Freud's (1900/1953) emphasis on the sexual nature of dreams to be excessive and even dogmatic: "Through his intense focus upon the neurotic, infantile, and sexual aspects of dreams, Freud gave dreams a bad name" (p. 139). Nor did Van de Castle agree that Freud's theory merits the name of science:

Although Freud constantly referred to his studies as "scientific" he certainly did not follow the methods of quantification generally accepted as necessary to merit that label. He provided no ratings, rankings, percentage figures, tables, graphs, or statistics to document his claims (p. 139).

We argue below that Freud's emphasis on the regressive and libidinal, object-seeking aspects of dreams was more accurate than conventionally believed and that his theory constitutes a viable scientific hypothesis on the nature of the dream.

Despite these largely negative assessments of Freud's (1900/1953) work on dreams by modern neuroscience, there is still some acceptance of the view that dreams have some kind of regulatory role to play in the emotional 
economy of the psyche (see articles in Moffitt, Kramer, \& Hoffman, 1993). Nevertheless, even those scientists who concede a relation between dreaming and emotion tend to dismiss Freud's notions about the infantile and sexual nature of the dream as largely outdated or even disproven. Having extensively reviewed the scientific literature, however, we argue that such a position is premature if not unfounded.

In this article, we present the case for a bonding and attachment function of REM sleep-a major physiological correlate of vivid dreaming. We hope to show that Freud's (1900/1953) position on the nature of the dream is consistent with the modern psychobiology of REM sleep when considered within the framework of the attachment hypothesis. In addition, we argue that the attachment hypothesis enriches psychoanalytic theory in a number of ways and carries with it important implications for a deeper understanding of the relation of dreaming and psychopathology. We begin with a short review of the psychobiology of REM sleep, followed by a review of the evidence supporting the role of REM sleep and dreaming in promoting attachment. We conclude with a reexamination of a number of psychoanalytically based theoretical concepts in light of the attachment hypothesis, and outline the hypotheses derived from this theory.

\section{REM Sleep}

REM sleep occurs approximately every 90 min during sleep and is associated with a number of other biological phenomena including paralysis in the antigravity muscles, genital arousal in both men and women, ${ }^{1}$ pontine-geniculooccipital spikes in the visual and association areas of the cortex, brain wave activity like that in the waking state, and release of various hormones important in reproductive and social behaviors (see below). It may also be associated with a daytime 90 min daydreaming rhythm (Broughton, 1982). This ultradian daydreaming rhythm has been associated with sexual arousal

IVan de Castle (1994, pp. 235-239) provided a recent review of the research on sexual arousal in REM sleep. The reliable association between REM and genital arousal in males is well established. And, although commensurate research on female genital arousal during REM has been limited, owing in large part to the lack of appropriate measurement procedures, there is evidence that females demonstrate a marked increase in genital circulatory activity during REM sleep (measured by vaginal pulse amplitude [VPA]) that is similar to waking sexual arousal, significantly higher than in other stages of sleep, and comparable to that found in males. Indeed, akin to nocturnal penile tumescence, Van de Castle suggested that with expanded research the measurement of VPA during REM sleep may potentially be of utility in the assessment of physiologically based deficits in sexual response. 
and sexual fantasies (Kripke \& Sonnenschein, 1978). Selective deprivation of REM sleep over the course of a few nights produces a compensatory increase in the amount of time spent in REM on subsequent nights termed REM rebound (Dement, 1960) and an increase in reported drive-related and sexual behaviors (Dement, 1965, Hirshkowitz, 1993). Finally, REM sleep is often, though not invariably, associated with vivid dreams (Dement \& Kleitman, 1957; Foulkes, 1985; Siegel, 1993). The time spent in REM progressively increases over the course of the night (McCarley, 1989). Participants in sleep studies report a greater frequency of childhood memories occurring in these long-duration REM episodes/dreams than in dreams from earlier portions of the night (Van de Castle, 1994).

Many regions of the brain, especially limbic, cingulate, and cortical association areas, sustain very high brain activation levels during REM sleep (Gillin, Buchsbaum, \& Wu, 1993). Limbic and cingulate cortices are densely interconnected with orbitofrontal cortex. This region of the frontal lobes in humans is known to be important for regulation of emotional and social behaviors (Oscar-Berman, McNamara, \& Freedman, 1991). Orbitofrontal lesions have been associated with REM sleep suppression and fragmentation (Skinner, Molnar, \& Harper, 1989; Jus et al., 1973). Interestingly, in the few mammalian species without REM sleep (the echnida and some cetaceans), orbitofrontal and related insular cortices have grown disproportionately large relative to the size of the frontal regions in humans (Winson, 1985; Morgane, Jacobs, \& McFarland, 1980). Presumably, these hypertrophied brain areas in the echnida and in cetaceans are performing functions that REM sleep performs for most other species.

\section{Evolution of REM Sleep}

REM sleep seems to have evolved almost exclusively in mammalian species (Winson, 1985; Zepelin, 1989), although some species of birds experience REM-like episodes (Kaufman, 1993). That virtually all mammals experience REM sleep raises the central question as to why this is so. One distinctive trait of mammals is that the young of many mammalian species are born in an immature state (altriciality). The infant is dependent on adult caretakers for a prolonged period. REM sleep, in fact, seems to be especially important for newborns. In most species, the proportion of time spent in REM sleep is greater in the immature (newborn) state than in the adult state (Roffwarg, Muzio, \& Dement, 1966). Interestingly, some species of birds are also born in an immature state, but it is not yet known whether these are the same species that demonstrate signs of REM. In the mammalian kingdom, the proportion of time spent in REM sleep varies with the altriciality of the species (Siegel, 
1993; Zepelin, 1989). Opossums and ferrets, for example, are born in an extremely immature state. These animals devote about $30 \%$ of their total sleep time to REM (Siegel, 1993). In terms of altriciality, humans are intermediate between opossums or ferrets and horses or elephants. Not surprisingly, therefore, adult humans spend a little less time (24\% of total sleep time) in REM sleep relative to opossums or ferrets, and a little more time in REM sleep than horses or elephants (which spend approximately $22 \%$ of their total sleep time in REM). Thus, REM sleep seems to be important for some aspect of development in mammalian species.

We suggest that REM sleep selectively activates the biobehavioral systems necessary to promote and maintain attachment between the young and the caretaker-mother. Bonding (with a mother) in infancy is critical for the well-being and perhaps even for the survival of the infant. Studies on maternal separation and deprivation in monkeys have consistently demonstrated a range of deleterious effects on the developing infant. These negative effects range from failure to thrive to death (see Reite \& Field, 1985, for a recent review). Interestingly, these separation studies have also revealed that sleep is implicated in virtually every aspect of the attachment process. We turn now to a brief review of the attachment literature as it relates to REM sleep.

\section{Attachment}

In their review of the neuroanatomical structures that mediate attachment, Steklis and Kling (1985) concluded that limbic system sites (especially the amygdala), the anterior temporal cortex, and the orbital frontal cortex were critical for attachment. Lesioning any of these three sites produces profound disruption in attachment processes. These forebrain regions seem to play a special role in regulating homeostasis, adaptive behaviors, and emotional behaviors-all important processes in the development of attachment. And, as mentioned above, limbic and cingulate-frontal regions are among the sites that evidence the highest activation levels during REM sleep. Thus, there appears to be some overlap between the anatomy of attachment and the anatomy of REM sleep.

To understand the relevance of attachment phenomena to REM sleep and dreaming, it is important to explore the nature of the attachment experience. That experience has most often been called love, but some attachment theorists have pointed to more basic and less loaded or emotionally laden terms to describe attachment, including symbiosis and synchrony. Reite and Capitanio (1985), for example, have defined attachment as "a neurobiologically based and mediated biobehavioral system, one of whose major functions is to promote the development and regulation (or modulation) or psychobiological 
synchrony between organisms" (p. 224). By synchrony, these authors mean the attunement of biological rhythms in one organism to those in another. Field (1985) cited a long list of behavioral and biological variables that have been documented to display synchrony of one kind or another in organisms undergoing attachment. Among these variables are sleep states and EEG waveforms. Synchrony and attunement of physiological variables such as autonomic indices and EEG waveforms may help each member of the attached pair to better regulate their own internal physiological systems. Synchrony may, in fact, be rightly construed as a need or basic drive. Beebe, Gertsman, and Carson (1982), Bernieri, Reznick, and Rosenthal (1988), and Belsky and Nezoworski (1988), among others, have documented the role of synchrony in the attachment process (in humans) between mothers and infants. Poor attachment is reliably associated with disruption in the normal synchronous interaction between mother and infant. Disruption of REM sleep following mother-infant separation is common (see Kalin \& Carnes, 1984, and Reite \& Capitanio, 1985, for recent reviews). Not surprisingly, in a well-controlled study on mother-infant attachment, a comparison of home-based versus communal sleeping arrangements of infants in Israeli Kibbutzim by Sagi, van IJzendoorn, Aviezer, Donnell, \& Mayseless (1994) revealed profound differences in security of attachment on the basis of sleeping arrangement. Those infants who slept in communal settings evidenced significantly more attachment problems than those who slept in home-based settings with parents. This was particularly striking inasmuch as the groups of families were closely matched (for potentially intervening variables), the quality of daily care was equivalent across group, and no differences were found in mother-infant interaction. Moreover, the infants in both groups spent greater than $40 \mathrm{hr}$ per week in daycare. The sleeping arrangements per se seemed to effect striking differences with respect to security of attachment.

Attachment processes are mediated by specialized neurohormonal systems. Neurohypophysial hormones like oxytocin and vasopressin, as well as arginine vasotocin, seem to be especially important for attachment and other social and sexual behaviors (see articles in Pedersen, Caldwell, Jirikowski, \& Insel, 1992). All three hormones promote sexual and social behaviors in a vast array of species. Oxytocin, for example, like REM sleep, is found exclusively in mammals. It is synthesized in the hypothalamus and is released from the neurohypophysis to induce uterine contraction during labor and milk ejection during nursing. When injected centrally it induces several of the behaviors associated with attachment in mammals (e.g., contact with young, care-taking behaviors, and species-typical reproductive behaviors; Insel, 1992). Oxytocin plays a central role in the expression of maternal behavior, sexual behavior, social bond formation, grooming, memory and learning, autonomic regulation, 
feeding, and yawning (Argiolas \& Gessa, 1991). This last function (yawning) is particularly interesting given its relation to sleep. When yawning is induced in rats via centrally administered oxytocin it is invariably associated with penile erection (Melis, Stancampiano, \& Argiolas, 1992). Penile erections occur exclusively in the REM state during sleep. Finally, oxytocin appears to display a sleep-sensitive pattern of release in humans, with peak levels occurring at about 4 o'clock in the morning (when REM sleep begins to predominate over non-REM (NREM) sleep; Forsling, 1993). In summary, in terms of attachment-related systems, REM sleep is associated with limbic forebrain activation, oxytocinergic release, sexual arousal, and dreaming.

Having laid out the major empirical findings in support of an association between REM sleep and attachment, we turn now to an explicit formulation of the attachment hypothesis, and then we discuss some anticipated objections to the hypothesis. We conclude with a reexamination of some central psychoanalytic ideas concerning dreaming and a review of the implications for psychopathology.

\section{Hypothesis}

REM sleep selectively activates the biobehavioral systems (limbic forebrain, oxytocinergic neurohormonal systems, etc.) necessary to promote and maintain attachment between the young and the caretaker. In the mature state, REM sleep may promote sexual pair bonding between adults and serve related and important compensatory functions as well. We suggest that the system elements that function in attachment in humans are as follows: (a) REM sleep (as described above and identified by desynchronized, low amplitude EEG activity, rapid eye movements, twitching of the extremities, and postural atonia); (b) vivid REM-associated dreaming, which functions to (1) lay the basis for daytime object or attachment-seeking behaviors by constructing a search image or internal working model of the attachment object, ${ }^{2}$ and (2) allow for some gratification of REM-activated libidinal impulses by promoting elaborate symbiotic fantasy and related affect states; (c) nighttime physiological synchrony (as described above) with a sleeping partner; and (d) daytime "search behaviors" that (1) are guided by the internal working model or search image

${ }^{2}$ We assume that the well-documented learning and memory consolidation effects associated with REM sleep (see, e.g., discussions in Foulkes, 1985; Hobson, 1988; Levin, 1991; Winson, 1985) play a role here. To construct an internal working model of the search image, one needs to develop a memory representation of the search image. Dreaming involves, among other things, the cognitive mnemonic processing associated with the development and revision of the search image. 
of the attachment object, (2) are periodically activated in association with a 90 min daytime daydreaming rhythm, and (3) function to maintain contact with the attachment object (evolving from physical to representational).

Our model implies the following causal relations: A biological clock periodically activates REM (and an associated daytime daydreaming activity). REM in turn activates physiological processes (e.g., activation of limbic and oxytocinergic brain systems) that support and promote attachment. Attachment is promoted along two pathways while asleep: biological synchrony with the bed partner and dreaming. Synchrony refers to the attunement of the biological rhythms of each person in the dyad with one another. This synchrony of rhythmicity helps to regulate biological cycles in each member of the dyad. This is true physiological symbiosis-attachment. Co-sleeping of mother and infant might promote this kind of physiological symbiosis-attachment. The infant uses the mother to regulate its biological processes; this is one aspect of attachment. When dreaming is recruited to support the goal of attachment, it probably contributes to the construction of an internal cognitive working model of the attachment object. This model is then used as a kind of unconscious search image that guides waking daytime fantasies and behaviors that promote attachment. In summary, we argue that REM sleep is one causal factor (not just a moderating variable) in promoting attachment.

We do not, however, wish to overstate the case for a causal role for REM in attachment. REM is a necessary but not sufficient condition for attachment. In addition to REM, an individual requires a host of other factors for attachment to occur. Among these other factors are a cooperative partner; persistent, goal oriented (e.g., proximity seeking) daytime behaviors; and the like. We do argue, however, that without periodic activation of the neurohormonal systems that incline an individual to attachment (i.e., without REM and its associated $90 \mathrm{~min}$ daydreaming rhythm), all of the other attachment-related factors would lose their potency in the attachment process. Attachment is too important a function to leave solely to conscious or learned behaviors. Similarly, as noted below, we do not suggest that the sole function of REM sleep and dreaming is related to attachment, but that it is the earliest (phylogenetically and ontogenetically) and most important function.

We turn now to some questions and objections raised by the hypothesis.

1. The first issue concerns the problem of whether both organisms need to be in REM sleep simultaneously for attachment to occur. Although such a situation would certainly enhance prospects for attachment, it is not required by the theory. All that is required is that REM sleep activates the circuits that incline the organism to attach to an appropriate object. REM or active sleep, for example, might help the infant (to attach) by (a) promoting synchrony with the caretaker, and (b) enhancing libidinal striving or need-object-seeking 
behaviors such as crying, cooing, babbling, and so on. The increased number of arousals associated with active sleep-REM sleep in the infant would promote attachment because these arousals elicit caretaking behaviors (e.g., nursing) from the mother. With respect to the mother's role, REM sleep would promote the inclination to bond with the baby by activating those brain systems needed for attachment and approach behaviors. For the adult pairbonding process, REM sleep promotes attachment by repeatedly activating brain systems that incline the individual toward attachment behaviors and by repeatedly rehearsing libidinal object search strategies.

2. One possible objection to the hypothesis is that REM sleep's wellknown role in learning and long-term memory consolidation is the real factor in attachment, not REM sleep physiology per se. Indeed one prominent hypothesis concerning the function of REM sleep is that it promotes learning and central nervous system (CNS) development. Roffwarg et al. (1966) argued that REM sleep serves to promote CNS development by providing periodic bursts of stimulation to the system. The problem with this learning perspective is that it is too general. It does not explain (a) why REM sleep is associated with selective activation of limbic and visual association areas; (b) why REM sleep is associated with sexual arousal; (c) why REM deprivation leads to heightened libidinal states; and (d) why REM sleep persists into the adult state. Learning and memory are surely required for attachment and are surely involved in REM sleep and dreaming. Yet, as we have pointed out, REM sleep selectively activates those brain and neurohormonal systems that are implicated in social, emotional, and reproductive behaviors. Our hypothesis predicts that REM sleep does indeed promote learning, but it is largely (though not exclusively) a selective type of learning: Attachment-related memories are given priority.

3. Another possible objection to our hypothesis concerns the heterogeneity of REM characteristics across species and across individuals within species (the problem of individual differences in REM characteristics). Because, for example, REM duration varies (e.g., with altriciality) across species, doesn't that imply that the functions of REM will also vary across species? Similarly, because REM characteristics vary somewhat among individuals within a species, REM functions might also vary. Why should REM perform one function across all species? Our hypothesis does not require a single uniform function for REM across all species or even within a species. REM and dreaming probably have several functions. We argue (for reasons reviewed above) only that one of the (phylogenetically and ontogenetically) earliest and most important functions of REM is attachment. In general, attachment-related functions of REM should be more pronounced in K-selected species (and individuals) as opposed to $r$-selected species and individuals. $r / \mathrm{K}$ selection 
theory (see Lancaster \& Lancaster, 1987, for a review relevant to attachment issues) originated in population biology and refers to two different reproductive strategies adopted by a species or an individual given certain environmental conditions. The $r$ strategy involves rapid maturation of individuals, reduced parental investment (therefore insecure attachment) in care of the young, relatively short life spans, and multiple and opportunistic sexual liaisons. The $\mathrm{K}$ strategy, by contrast, involves delayed maturation rates, high parental investment (more secure attachments) and long-term sexual pair-bonding (see also Belsky, Steinberg, \& Draper, 1991, for discussion). Our theory would predict that in individuals and species who are r-selected, REM indices would be correspondingly reduced but not eliminated. All mammalian species are $\mathrm{k}$-selected relative to nonmammalian species.

4. Other possible objections to the theory arise when one considers predictions that flow from the theory. The theory predicts, for example, disruption of attachment when REM is blocked or disrupted. However, to clearly demonstrate a causal role for REM in this instance it would be necessary to rule out possible confounding influences. Disruption in attachment could be due to whatever caused the REM disruption in the first place, or to the lack of sleep associated with REM disruption, and so on. REM deprivation studies are notoriously difficult to interpret. At present, no firm conclusions regarding the functions of REM sleep can be drawn from these studies. When careful reviews of the REM deprivation literature are conducted, one finding consistently emerges: Drive-related behaviors (e.g., sexual appetite) increase. We discuss this issue below.

A related issue involves disentangling the causal influences in the depression-related symptomology that is often associated with marital separation, divorce, or loss of a loved one. Disruption of REM in these cases occurs after disruption in the (attachment) relationship. Instead of blocking REM and then getting disrupted attachment, one begins with the dissolution of a long-term attachment and ends up with disrupted REM sleep indices. Although the dissolution of the relationship is the primary cause of the depression, it may be that vegetative signs, the persistence and severity of the depression, or both are related to the severity of the REM disruption. These are all empirical issues that the attachment hypothesis can accommodate. The theory also predicts that if REM is blocked in the mother (say a mother rat), the infant will not be able to securely attach to her. Blocking REM in the infant will prevent that infant from attaching to anyone.

One other interesting prediction of the theory was brought to our attention by an anonymous reviewer: If one aspect of REM-mediated attachment involves biological synchrony between mother and infant, and if synchrony is more easily attained between genetically related individuals, then 
attachment in general should be more easily attained between people who are genetically related. A mother will more easily synchronize with an infant who shares $50 \%$ of her genes than she would with an adopted infant. However, it should be pointed out that synchrony is possible with any couple who co-sleeps.

To this point, we have presented the major empirical and physiological findings that support our contention that one of the central functions of REM sleep is related to promoting attachment. We have attempted to integrate data from the neurosciences and evolutionary psychology, and to render rather general conclusions that are generically relevant for both human and animal study. In the following section, we more specifically discuss the relationship of the presumed attachment function of REM sleep to psychoanalytic theory and psychopathology research. In so doing, we hope to further elucidate the present theoretical framework and demonstrate the complementarity, heuristic value, and practical implications of the attachment hypothesis.

\section{REM Sleep and the Activation of Libidinal Striving}

Freud (1900/1953, 1916/1961) argued that the latent content of most dreams represented a revival of infantile libidinal strivings. If REM sleep is designed to promote attachment, then one strategy would be to reactivate the systems used by infants to attach to a caregiver. Some current theories of love and adult pair-bonding conceptualize romantic bonding as an extension of basic attachment processes (Shaver, Hazan, \& Bradshaw, 1988). As noted above, these processes incorporate physiology involved in sexual arousal, affect modulation, and object seeking.

We suggest that for individuals in the immature state, REM sleep promotes bonding between the infant and the caretaker, and hence adaptation. The finding that sleeping away from parents results in significantly less secure attachment, for example, supports this contention (Sagi et al., 1994). REM sleep in individuals in the adult state similarly promotes libidinal striving and attachment and can, through the expression of such gratifying wishes (e.g., symbiotic fantasies), serve a palliative function generally and especially during times of stress. Indeed, we argue that the decreased REM latency typically found in a range of disorders hypothetically related to disturbances in attachment and object relations may represent a compensatory mechanism. We address this point below. We also suggest that the function of REM sleep is concomitantly directed toward impulse modulation-expression and the activation of object search strategies. As this suggests, REM sleep would be expected to have a drive-dampening effect. Not surprisingly, the only consistent effect associated with REM deprivation in humans and animals is an increase in 
drive-related behaviors-especially hypersexuality (Hirshkowitz, 1993; Vogel, 1993). No other obvious psychological effects are noted after REM deprivation because it takes time to notice disruption in an individual's ability to attach to others. The hypothesis, however, predicts that people selectively deprived of REM should be less able to establish synchrony (e.g., verbal synchrony) with another as compared to suitable controls (e.g., NREMdeprived people). It also follows that those with significant interpersonal difficulties, disturbed attachments, impairment in object relations, and the like would have anomalies in REM sleep architecture (and correspondingly, dream content).

\section{Integration With Psychoanalytic Theory}

\section{Freud's Theory of the Dream}

According to Freud (1900/1953), dreams represent the disguised expression and fulfillment of repressed wishes deriving from early childhood. For him, such wishes were primarily libidinal in nature, doubtlessly expressed differentially through the lens of psychosexual development. Akin to Fairbairn (1954), we argue that these libidinal wishes can profitably be understood as objectseeking in nature. Owing to the ostensibly unacceptable nature of the libidinal strivings (i.e., wishes) to the conscious mind, the psychic apparatus of the censorship system transforms the latent wish through displacement, condensation, and symbolism into the manifest content of the dream, parallel to the compromise formation seen in neurotic symptoms. Correspondingly, whereas the dreams of young children were viewed as relatively transparent embodiments of wishes, the dreams of latency-aged children were both more complex and disguised, owing to their greater cognitive capacity as well as the introjection and crystallization of superego functions that render libidinal wishes unacceptable (i.e., anxiety arousing and therefore sleep hindering). Although this characterization is somewhat oversimplified, and does not detail the developments of his theorizing on dreams throughout his life, our aim is to establish a framework for integration with the psychobiological findings outlined above. The reader desiring a more thorough account of the development of Freud's writings pertinent to dreaming is referred to McLeod (1992), among others. And, as McLeod so aptly noted, Freud did indeed acknowledge that dreams were the product of both unconscious and conscious (i.e., ego) processes, embedded ultimately in his structural theory. Consequently, an analysis of the manifest content in terms of conflict and problem-solving attempts (i.e., ego functions), of the dream work itself, as well as the latent material may all shed light on the broader phenomenal experience and meaning of the dream. Indeed, many have proposed that the function of dreams 
is essentially that of mastery and problem solving and at times have failed to fully appreciate the concordance of their views with Freud's later writings.

Nevertheless, we assert that dreams are at least partially related to disguised wishes that are libidinal and regressive in nature. As mentioned above, the attachment hypothesis predicts specific adaptive functions of REM sleep that are concordant with Freud's (1900/1953) theorizing as well as with more contemporary developments in psychoanalytic research. REM appears to play a significant role in fostering and facilitating synchrony and attunement in the young child. In addition, we argue that although not as crucial in later years, REM does indeed promote and reinforce attachment and sexual bonding in the adult by means of activation and modulation of libidinal impulses and object-seeking behavior.

\section{REM, Ego Development, Adaptation, and Psychopathology}

Owing to our suggestion pertaining to REM's role in the regulation of attachment mechanisms, we hypothesize that REM similarly plays a role in fostering the development and consolidation of a coherent sense of self in the developing child. Although there is a relative lack of consensus regarding the elucidation of this developmental process, what is clear is that the development of the self occurs within an interactional, interpersonal matrix of evolving complexity and integration as the child grows from dependence to autonomy. Investigators spanning the spectrum of theoretical perspectives within psychoanalysis, including ego, self, and object relations viewpoints, have uniformly appreciated the interpersonal basis for the development of personality organization and would include Erikson, Hartmann, Kohut, Winnicott, and Mahler, to name a few. According to Mahler (Mahler, 1968; Mahler, Pine, \& Bergman, 1975), the process of the development of a coherent sense of self is sequential, beginning with symbiotic attachment as a necessary precursor to individuation, and empathic failures in the mother-infant dyad disrupt this process and play an etiological role in adult psychopathology. This view has been challenged by others, most notably by Stern (1985), who pointed out that the tasks of attachment and dependency are lifelong and not limited to early "stages" of development and that the process of increasing differentiation and complexity of relatedness derives from early infancy. Similarly, as reviewed by Nehum (1994) in this journal, Louis Sander "has been adumbrating a remarkably complex and detailed theory of (early) development over the last 30 years" (p. 2). Borrowing from systems theory, Sander has documented and described the evolving interpersonal process of development between infant and caretaker, and has underscored the importance of what he terms state contingent 
caregiving leading first to entrainment of biorhythms and subsequently to the capacity for self-regulation.

A more thorough review of developmental theories and related research is well beyond the scope of this article. Even so, the commonalities across perspective pertain to the central importance of attachment and the evolving process of relatedness (from simple to complex, from dependency to autonomy, and from the physical to the representational), culminating in increasing differentiation, agency, and self-regulation. REM sleep, we suggest, buttresses this process on several levels both directly, by promoting the early bonding process so essential for entrainment and the maintenance of attachmentrelated behaviors, and indirectly. This indirect process, we believe, operates through the gratification of symbiotic, libidinal wishes expressed through the dream that serves as a palliative or soothing "holding state" enabling the child to systematically move away from the primary caretaker physically and psychologically. The link between the 90 min nocturnal REM rhythm and the 90 min daytime daydreaming rhythm is relevant here also. Presumably, periodic (every $90 \mathrm{~min}$ ) activation of the biobehavioral systems responsible for attachment would provide the child with the two things it needs for successful individuation and ego development: a baseline level of libidinal gratification (facilitating self-regulation) and initiation of object-seeking behaviors. Moreover, we argue that REM sleep serves a similar ego-mediation function throughout the lifespan. During times of stress, upheaval, or real or imagined losses, such a function would be evidenced most clearly. We expect that there would be a greater reliance on REM during such periods. Indeed, as discussed below, decreased REM latency (i.e., entering REM faster upon falling asleep) consistently has been found to be associated with a range of psychological disorders, particularly depression.

According to Freud (1916/1961), the early libidinal attachment of the infant centering around oral activity "is the starting point of the whole of sexual life, the unmatched prototype of every later sexual satisfaction, to which fantasy often enough recurs in times of need" (p. 314). Several theorists have since written about the presumed adaptation-enhancing effect of symbiotic fantasies, most notably Lloyd Silverman and his colleagues. According to Silverman (e.g., Silverman, 1983; Silverman \& Weinberger, 1985), a powerful source of human motivation derives from the unconscious wish for a state of oneness, or symbiosis, with another person-prototypically, the "good mother" of early infancy. Moreover, Silverman (1983) asserted that the subliminal stimulation of this unconscious wish for a state of oneness can have an adaptation-enhancing effect, and has used the experimental stimulus Mommy and $I$ are one to experimentally investigate this claim. 
To date, a sizeable body of literature has accrued that has demonstrated the differential, adaptation-enhancing impact of stimulating symbiotic fantasies with a variety of populations. In patient samples, subliminal symbiotic stimulation has been shown to significantly augment the efficacy of a variety of treatment modalities across the patient population, including inpatient treatment of schizophrenics (Silverman et al., 1975); residential treatment of adolescents (Bryant-Tuckett \& Silverman, 1984); assertiveness training (Packer, 1984); group counseling (Linehan \& O'Toole, 1982); and the behavioral treatment of obesity (Silverman, Martin, Ungaro, \& Mendelsohn, 1978), smoking (Palmatier \& Bornstein, 1980), and insect phobia (Silverman, Frank, \& Dachinger, 1974). In nonpatient samples, the effect of subliminal symbiotic stimulation has been demonstrated to increase academic performance (Parker, 1982) and to eventuate significant anxiety reduction in college students (Garske, 1984).

Although the results of the relatively voluminous body of literature on the subliminal activation of oneness fantasies have not been uniformly supportive, an extensive review of studies conducted outside the realm of Silverman's laboratory and/or supervision has demonstrated that those studies supporting his thesis outnumber those in which results were disconfirming by a ratio of 3:1 (Silverman, 1983). When including those studies conducted by Silverman, and by his colleagues and students, this ratio is significantly enhanced. A more recent meta-analytic study of this literature found that the subliminal activation of symbiotic fantasies produces "a modest but reliable improvement in adaptive behavior" (Hardaway, 1990, p. 184).

It is our contention that REM performs similar, adaptation-enhancing functions both physiologically and psychologically by promoting libidinal strivings and unconscious symbiotic fantasy. This assertion is not without empirical support, although the mechanism by which REM operates is undoubtedly open to conjecture and further test (which we propose below). Indeed, we suggest that the activation of sexual arousal during REM sleep could be considered a physiological manifestation of the libidinal striving and symbiotic fantasy expressed in the latent content of dreams. The effect of subliminally stimulating symbiotic fantasies on REM sleep architecture and dream content, although not yet studied, is illustrative. The theoretical framework we are advancing offers specific predictions, as discussed below. It is to this that we now turn, examining the relationship between REM and psychopathology.

Cartwright (1986) conducted a sleep study of adults experiencing marital separation with and without concommitant depression. Compared to those of nondepressed separating and married controls, the dream reports of the depressed group were significantly shorter (until the depression abated at a 1- 
or 2-year follow-up, a point that will be taken up below), were characterized by themes of nurturance and abasement, and were dominated by a "past-oriented time frame." People in the depressed group were more likely to wake at night's end from a dream in which negative emotions prevailed and had more dreams in which they were alone. It would appear that depression, and other disorders as well, is characterized by a breakdown in the compensatory function of dreams. It would also seem that decreased REM latency represents an attempt, both physiologically and psychologically, to compensate. Indeed, upon followup, Cartwright discovered that those who were depressed and evidenced decreased REM latency made a "fairly good adjustment" and were no longer " depressed, whereas those depressed individuals whose REM latency was normal remained depressed (Cartwright, Kravitz, Eastman, \& Wood, 1991). Interestingly, studies of schizophrenics have also shown that acute psychotic decompensation is related to deficits in REM, whereas those nearing remission evidence significant increases in REM (as reviewed by Gierz, Campbell, \& Gillin, 1987). It remains to be demonstrated, however, whether the changes in REM play a causal, compensatory role and, if so, if the mechanism is concordant with the theory outlined herein.

With respect to REM latency, numerous studies have demonstrated that various patient samples experience decreased REM latency relative to controls, including those evidencing schizophrenia (e.g., Hudson et al., 1993), borderline personality disorder (Akiskal, Yerevanian, Davis, King, \& Lemmi, 1985; McNamara et al., 1984), obsessive-compulsive disorder (Insel et al., 1982) and, most typically, depression (e.g., Giles, Roffwarg, \& Rush, 1990; Reynolds, 1987). The nature and function of this decreased latency, however, has not been fully clarified to date. Indeed, this confusion is most pronounced with respect to the findings of an antidepressant effect associated with REM deprivation. Inasmuch as REM deprivation has been associated with increases in drive-related behavior (both sexual and appetitive), this may speak to the palliative effects associated with REM deprivation. However, some have argued that it is the REM rebound effect that is palliative (e.g., Cartwright, 1991), whereas others have attributed the antidepressant effects more directly to REM deprivation per se (e.g., Wu \& Bunney, 1990). It is important to note that the prototypical decreased REM latency found among depressives as a group is, upon closer inspection, essentially bimodal. As Schulz and Lund (1985) have documented, the first REM episode begins either within 20 min or after 60-70 min.

In keeping with the theoretical framework we are presenting, we suggest that these ostensibly conflicting findings may be due to the failure to appreciate and appropriately assess differing subtypes of depression. According to Sidney 
Blatt (e.g., Blatt, 1974; Blatt, Quinlan, Chevron, McDonald, \& Zuroff, 1982; Blatt \& Zuroff, 1992), among others, there are two primary depressive subtypes that Blatt refers to, respectively, as anaclitic and introjective. The anaclitic subtype refers to dysphoria that is interpersonally driven, where the person is fearful of loss of the availability and affection from others, is overly dependent and intensely desirous of closeness, has difficulty overtly expressing anger, and experiences helplessness and loneliness in the face of interpersonal disruption. By contrast, the introjective subtype refers to dysphoria centering around concerns of self-definition and self-worth, and in the face of threats to self-esteem, experiences dysphoria that is characterized by feelings of failure, incompetence, and loss of autonomy. Consequently, we argue that anaclitic depressives would be most likely to evidence significantly decreased REM latency owing to their greater striving for attachment to others. This is certainly a testable hypothesis (i.e., comparing anaclitic and introjective depressives on REM latency) and could be accomplished by using Blatt's Depressive Experiences Scale (DEQ), which he developed to study depressive subtypes. Similarly, it would be useful to determine whether the subliminal stimulation of symbiotic fantasy would be particularly palliative for these persons (and in so doing, increase REM latency much as was found in Cartwright's, 1991, study reported above). It should be pointed out that preliminary results from Zborowski's laboratory, investigating dream content among psychometrically defined anaclitic and introjective young adults, have revealed that a substantial number of anaclitic individuals report dreams in which they are predominately or completely alone and significantly more so relative to introjectives (Zborowski \& David, 1997). It would follow from our theory that these individuals would also evince shorter REM latency. Lastly, a comparison of individuals high and low in dependency in terms of sleep architecture (i.e., REM latency and density) would be illustrative.

\section{Censorship, Repression, and Disguise}

Our speculation about the role of REM in promoting libidinal attachment and adaptation throughout the lifespan begs the obvious question, that of why it would be necessary to disguise the ostensibly latent, libidinal wishes from conscious awareness. For Freud (1900/1953, 1916/1961), such censorship was paramount to maintaining sleep. That is, dreams were disguised as a way of staving off the anxiety associated with the unacceptable nature of the libidinal wish while at the same time permitting expression of that wish-albeit in a disguised manner. We suggest two additional reasons that are not incompatible 
with Freud's theorizing. Our first suggestion concerning the function of censorship centers around anxiety-reducing strategies, whereas the second is more mechanistic in spirit.

To promote synchrony and attachment, we have argued that REM sleep activates specific biobehavioral systems as well as symbiotic fantasy in the dream. We suggest that, at the level of consciousness, symbiotic wishes would represent a threat to self. The level of threat would no doubt vary as a function of the integrity of ego development, representing at the extreme an annihilation of self. Correspondingly, those with relative deficits in the sense of self would be more likely to experience anxiety dreams. The finding of more frequent nightmares and anxiety dreams among people with so-called "thin" ego boundaries would support this claim (e.g., Hartmann, 1989), as do Max Stern's (1988) data showing an increase in anxiety dreams among those with self pathology. Additionally, Silverman and his colleagues found that the subliminal activation of symbiotic fantasies reliably eventuated adaptation, anxiety reduction, greater levels of independent functioning, less reliance on food or other substances, and the like, across populations. Such effects, however, appear to be mediated by the level of differentiation of self (i.e., "differentiation from mother"). Positive effects were seen to the extent that participants possessed an adequate level of self-differentiation. Those who lacked such differentiation, by contrast, failed to show ameliorative effects (as reviewed by Silverman, 1983, and Silverman \& Weinberger, 1985). Thus, symbiotic fantasies were believed to be adaptation enhancing only to the extent that the sense of self is preserved. Relatedly, we suggest that the function of the dream censor permits the expression of symbiotic, libidinal wishes and strivings while simultaneously protecting the sense of self. Indeed, when symbiotic stimuli are presented supraliminally, they typically have no effect and may even elicit anxiety (e.g., Silverman, 1972).

According to Silverman (e.g., 1972) when psychodynamic content is brought into awareness, its impact on behavior is diminished. This relates to our second suggestion regarding the function of the censorship system. In light of the central role of attachment in fostering the adaptation and indeed the survival of the child, attachment processes appear to function both automatically and unconsciously. Stated quite simply, nature cannot afford to place the survival of the infant and survival of the species (via reproduction) in the hands of conscious deliberation. To do so, as Silverman's work suggests, may impede the process. Rather, the attachment process, like REM sleep itself, appears to be innate, unlearned, automatic, and mediated by unconscious phenomena. 


\section{Conclusions}

We have argued that many of Freud's (1900/1953) insights into the nature and function of the dream are consistent with the attachment hypothesis of REM sleep, with the known physiologic correlates of REM sleep when viewed through the lens of the attachment hypothesis, and with the data deriving from evolutionary psychology. Our review of the literature on REM sleep and attachment strongly suggests that REM sleep does indeed involve activation of the biobehavioral systems important in attachment, which include sexual and object-seeking behaviors. The function of REM sleep that we have advanced helps to explain why dreaming is, as Freud argued, integral to ego development and normal maturation of the individual. The developing child is given, in part through REM sleep, a physiologic base that allows for the expression of libidinal striving and symbiotic fantasy and that at the same time enables both maturation and the establishment of object-seeking strategies. Freud's insights, when considered in terms of the attachment hypothesis, also help us to understand why sleep indices (both objective and subjective) vary across personality and psychopathologic syndromes. Indeed, many disorders theoretically derive from disturbances or disruption in attachment, and their sequelae. The attachment hypothesis therefore predicts specific REM sleep anomalies that both contribute to and reflect these difficulties. In so doing, we have sought to account for the wealth of data deriving from the study of REM sleep and psychopathology, and have offered a range of hypotheses that would provide an important test of the theoretical framwork outlined herein.

We have suggested, in conjunction with Freud's (1900/1953) theorizing and the known physiologic evidence (e.g., the sexual arousal that accompanies REM sleep and the findings of increased drive-related behavior in response to REM deprivation), that libidinal striving is preferentially activated during REM sleep. Thus, we also argue that the attachment hypothesis deepens our understanding of Freud's theory of the censorship system. In addition to serving an anxiety-reducing function and minimizing the threat to self that may accrue from the conscious awareness of symbiotic fantasy, we also suggest, rather mechanistically, that nature would not allow so important a need (attachment) to rely on conscious deliberation. Stated quite simply, libidinal strivings act to direct the behavior of the organism even in the absence of conscious awareness. We also suggest a concordance between the modern neuroscientific data and many of Freud's writings throughout his life (cf. McLeod, 1992), although that is beyond the scope of the present article. Indeed, although attachment may be one very important function associated with REM sleep, dreams doubtlessly reflect a variety of themes and concerns 
of the dreamer that are likely to be multiply determined by past, present, and future strivings.

In conclusion, Freud's (1900/1953) theory of the dream, when viewed in light of the attachment hypothesis, remains impressive in both neuroscientific and clinical terms. Contemporary dismissals of psychoanalytic theory regarding the nature and function of the dream seem no longer justified on scientific grounds. Even so, our larger aim was to provide an integrative theoretical framework of heuristic value that is strengthened by a cross-pollination and synthesis of ideas across disciplines. In circumventing parochialism, we believe we can broaden our understanding of the richness and relevance of REM sleep well beyond what is afforded by any single perspective.

\section{References}

Akiskal, H. S., Yerevanian, B. I., Davis, G. C., King, D., \& Lemmi, H. (1985). The nosologic status of borderline personality: Clinical and polysomnographic study. American Journal of Psychiatry, 142, 192-198.

Argiolas, A., \& Gessa, G. (1991). Central functions of oxytocin. Neuroscience and Biobehavioral Reviews, 15, 217-231.

Beebe, B., Gertsman, L., \& Carson, B. (1982). Rhythmic communication in the mother-infant dyad. In M. Davis (Ed.), Interaction rhythms: Periodicity in communicative behavior (pp. 79-100). New York: Human Sciences Press.

Belsky, J., \& Nezoworski, T. (1988). Clinical implications of attachment. Hillsdale, NJ: Erlbaum.

Belsky, J., Steinberg, L., \& Draper, P. (1991). Childhood experience, interpersonal development, and reproductive strategy: An evolutionary theory of socialization. Child Development, 62, 647-660.

Bernieri, F. J., Reznick, S. J., \& Rosenthal, R. (1988). Synchrony, pseudosynchrony, and dissynchrony: Measuring the entrainment process in mother-infant interactions. Journal of Personality and Social Psychology, 54, 243-253.

Blatt, S. J. (1974). Levels of object representation in anaclitic and introjective depression. Psychoanalytic Study of the Child, 24, 107-157.

Blatt, S. J., Quinlan, D. M., Chevron, E. S., McDonald, C., \& Zuroff, D. C. (1982). Dependency and self-criticism: Psychological dimensions of depression. Journal of Consulting and Clinical Psychology, 50, 113-124.

Blatt, S. J., \& Zuroff, D. C. (1992). Interpersonal relatedness and self-definition: Two prototypes for depression. Clinical Psychology Review, 12, 527-562.

Broughton, R. (1982). Human consciousness and sleep/wake rhythms: A review and some neuropsychological considerations. Journal of Clinical Neuropsychology, 4, 193-218.

Bryant-Tuckett, R., \& Silverman, L. H. (1984). Effects of the subliminal stimulation of symbiotic fantasies on the academic performance of emotionally handicapped students. Journal of Counseling Psychology, 31, 295-305. 
Cartwright, R. (1986). Affect and dream work from an information processing point of view. Journal of Mind and Behavior, 7, 411-428.

Cartwright, R. (1991). Dreams that work: The relation of dream incorporation to adaptation to stressful events. Dreaming, 1, 3-9.

Cartwright, R., Kravitz, H., Eastman, C., \& Wood, E. (1991). REM latency and recovery from depression: Getting over divorce. American Journal of Psychiatry, $148,1530-1535$.

Crick, F., \& Mitchison, G. (1986). REM sleep and neural nets. Journal of Mind and Behavior, 7, 229-250.

Dement, W. (1960). The effect of dream deprivation. Science, 131, 1705-1707.

Dement, W. (1965). Recent studies on the biological role of rapid eye movement sleep. American Journal of Psychiatry, 122, 404-408.

Dement, W., \& Kleitman, N. (1957). The relation of eye movements during sleep to dream activity: An objective method for the study of dreaming. Journal of Experimental Psychology, 53, 339-346.

Fairbaim, W. R. D. (1954). Psychanalytic studies of personality. London: Tavistock.

Field, T. (1985). Attachment as psychobiological attunement: Being on the same wavelength. In M. Reite \& T. Field (Eds.), The psychobiology of attachment and separation (pp. 415-454). New York: Academic Press.

Forsling, M. (1993). Neurohypophysial hormones and circadian rhythm. In W. North, A. Moses, \& L. Share (Eds.), The neurohypophysis: A window on brain function (pp. 382-395). New York: New York Academy of Sciences.

Foulkes, D. (1978). A grammar of dreams. New York: Basic Books.

Foulkes, D. (1985). Dreaming: A cognitive-psychological analysis. Hillsdale, NJ; Erlbaum.

Freud, S. (1953). The interpretation of dreams. In J. Strachey (Ed. and Trans.), The standard edition of the complete psychological works of Sigmund Freud (Vols. 4 \& 5). London: Hogarth Press. (Original work published 1900)

Freud, S. (1961). Introductory lectures on psychoanalysis: Part II. Dreams. In J. Strachey (Ed. and Trans.), The standard edition of the complete psychological works of Sigmund Freud (Vol. 15, pp. 83-239). London: Hogarth Press. (Original work published 1916)

Garske, J. P. (1984, August). Effects of subliminal activation on affective states. Paper presented at the 92nd Annual Convention of the American Psychological Association, Toronto, Ontario, Canada.

Gierz, M., Campbell, S. S., \& Gillin, J. C. (1987). Sleep disturbances in various nonaffective psychiatric disorders. Psychiatric Clinics of North America, 10, 565581.

Giles, D. E., Roffwarg, H. P., \& Rush, J. A. (1990). A cross-sectional study of the effects of depression on REM latency. Biological Psychiatry, 28, 697-704.

Gillin, J. C., Buchsbaum, M. S., \& Wu, J. C. (1993). Cerebral metabolism. In M. A. Carskadon (Ed.), Encyclopedia of sleep and dreaming (pp. 96-98). New York: Macmillan. 
Hardaway, R. A. (1990). Subliminally activated symbiotic fantasies: Facts and artifacts. Psychological Bulletin, 107, 177-195.

Hartmann, E. (1989). Boundaries of dreams, boundaries of dreamers: Thin and thick boundaries as a new personality measure. Psychiatric Journal of the University of Ottawa, 14, 557-560.

Hirshkowitz, M. (1993). Sex and sleep. In M. A. Carskadon (Ed.), Encyclopedia of sleep and dreaming (pp. 535-537). New York: Macmillan.

Hobson, J. A. (1988). The dreaming brain. New York: Basic Books.

Hudson, J. I., Lipinski, J. F., Keck, P. E., Jr., Aizley, H. G., Vuckovic, A., Zierk, K. C., \& Pope, H. G., Jr. (1993). Polysomnographic characteristics of schizophrenia in comparison with mania and depression. Biological Psychiatry, 34, 191-193.

Insel, T. (1992). Oxytocin and the neurobiology of attachment. Behavioral and Brain Sciences, 15, 515-516.

Insel, T. R., Gillin, J. C., Moore, A., Mendelson, W. B., Loewenstein, R. J., \& Murphy, D. L. (1982). The sleep of patients with obsessive-compulsive disorder. Archives of General Psychiatry, 39, 1372-1377.

Jus, A., Jus, K., Villeneuve, A., Pires, A., Lachance, R., Fortier, J., \& Villeneuve, R. (1973). Studies on dream recall of chronic schizophrenics after prefrontal lobotomy. Biological Psychiatry, 6, 275.

Kalin, N., \& Carnes, M. (1984). Biological correlates of attachment bond disruption in humans and nonhuman primates. Progress in Neuro-Psychopharmacology and Biological Psychiatry, 8, 459-469.

Kaufman, K. (1993). Birds. In M. A. Carskadon (Ed.), Encyclopedia of sleep and dreaming (pp. 76-78). New York: Macmillan.

Kripke, D. F., \& Sonnenschein, D. (1978). A biologic rhythm in waking fantasy. In K. S. Pope \& J. L. Singer (Eds.), The stream of consciousness: Scientific investigations into the flow of human experience (pp. 321-332). New York: Plenum Press.

Lancaster, J., \& Lancaster, C. (1987). The watershed: Changes in parental investment and family formation strategies in the course of human evolution. In J. Lancaster, J. Altman, A. Rossi, \& L. Sherrod (Eds.), Parenting across the lifespan: Biosocial perspectives (pp. 187-205). New York: Aldine De Gruyter.

Levin, F. M. (1991). Mapping the mind: The intersection of psychoanalysis and neuroscience. Hillsdale, $\mathrm{NJ}$ : Analytic Press.

Linehan, E., \& O'Toole, J. (1982). The effect of subliminal stimulation of symbiotic fantasy on college students' self-disclosures in group counseling. Journal of Counseling Psychology, 29, 151-157.

Mahler, M. S. (1968). On human symbiosis and the vicissitudes of individuation: Infantile psychosis. New York: International Universities Press.

Mahler, M. S., Pine, F., \& Bergman, A. (1975). The psychological birth of the human infant. New York: Basic Books.

McCarley, R. W. (1989). The biology of dreaming sleep. In M. H. Kryger, T. Roth, \& W. C. Dement (Eds.), Principles and practice of sleep medicine (pp. 173-183). Philadelphia: Saunders. 
McLeod, M. N. (1992). The evaluation of Freud's theory about dreaming. Psychoanalytic Quarterly, 61, 37-64.

McNamara, E., Reynolds, C. F., III, Soloff, P. H., Mathias, R., Rossi, A., Spiker, D., Coble, P. A., \& Kupfer, D. J. (1984). EEG sleep evaluation of depression in borderline patients. American Joumal of Psychiatry, 141, 182-186.

McNamara, P. (1996). REM sleep: A social bonding mechanism. New Ideas in Psychology, 14, 35-46.

Melis, M., Stancampiano, R., \& Argiolas A. (1992). Hippocampal oxytocin mediates apomorphine induced penile erection and yawning. Pharmacology, Biochemistry and Behavior, 42, 61-66.

Moffitt, A., Kramer, M., \& Hoffman, R. (1993). The functions of dreaming. Albany: State University of New York Press.

Morgane, P. J., Jacobs, M. S., \& McFarland, W. L. (1980). The anatomy of the brain of the bottlenose dolphin (Tursiops truncatus): Surface configurations of the telencephalon of the bottlenose dolphin with comparative anatomical observations in four other cetacean species. Brain Research Bulletin, 5, (Suppl. 5), 1-107.

Nehum, J. P. (1994). New theoretical vistas in psychoanalysis: Louis Sander's theory of early development. Psychoanalytic Psychology, 11, 1-19.

Oscar-Berman, M., McNamara, P., \& Freedman, M. (1991). Delayed response tasks: Parallels between experimental ablation studies and findings in patients with frontal lesions. In H. S. Levin, H. M. Eisenberg, \& A. L. Benton (Eds:), Frontal lobe function and injury (pp. 230-255). New York: Oxford University Press.

Packer, S. (1984, August). Subliminal activation of unconscious fantasies as an adjunct in behavior assertiveness training. Paper presented at the 92nd Annual Convention of the American Psychological Association, Toronto, Ontario, Canada.

Palmatier, J. R., \& Bornstein, P. H. (1980). The effects of subliminal stimulation of symbiotic merging fantasies on behavioral treatment of smokers. Journal of Nervous and Mental Disease, 168, 715-720.

Parker, K. A. (1982). The effects of subliminal merging stimuli on the academic performance of college students. Journal of Counseling Psychology, 29, 19-28.

Pedersen, C. A., Caldwell, J. D., Jirikowski, G. F., \& Insel, T. R. (1992). Oxytocin in matemal, sexual and social behaviors. Annals of the New York Academy of Sciences, 652.

Reite, M., \& Capitanio, J. (1985). On the nature of social separation and social attachment. In M. Reite \& T. Field (Eds.), The psychobiology of attachment and separation (pp. 223-258). New York: Academic Press.

Reite, M., \& Field, T. (1985). The psychobiology of attachment and separation. New York: Academic Press.

Reynolds, C. F., III (1987). Sleep and affective disorders. Psychiatry Clinics of North America, 10, 583-591.

Roffwarg, H. P., Muzio, J. N., \& Dement, W. C. (1966). Ontogenetic development of the human sleep-dream cycle. Science, 152, 604-619.

Sagi, A., van IJzendoorn, M. H., Aviezer, O., Donnell, F., \& Mayseless, O. (1994). 
Sleeping out of home in a Kibbutz communal arrangement: It makes a difference for infant-mother attachment. Child Development, 65, 992-1004.

Schulz, H., \& Lund, R. (1985). On the origin of early REM sleep episodes in the sleep of depressed patients: A comparison of three hypotheses. Psychiatry Research, 16,65 .

Shaver, P., Hazan, C., \& Bradshaw, D. (1988). Love as attachment: The integration of three behavioral systems. In R. J. Sternberg \& M. L. Barnes (Eds.), The psychology of love (pp. 68-99). New Haven, CT: Yale University Press.

Siegel, J. (1993). Function of REM sleep. In M. A. Carskadon (Ed.), Encyclopedia of sleep and dreaming (pp. 507-510). New York: Macmillan.

Silverman, L. H. (1972). Drive stimulation and psychopathology: On the conditions under which drive-related external events evoke pathological reactions. In R. R. Holt \& E. Peterfreund (Eds.), Psychoanalysis and contemporary science (Vol. 1, pp. 306-326). New York: Macmillan.

Silverman, L. H. (1983). A subliminal psychodynamic activation method: Overview and comprehensive listing of studies. In J. Masling (Ed.), Empirical studies of psychoanalytical theories (Vol. 1, pp. 69-100). Hillsdale, NJ: Analytic Press.

Silverman, L. H., Frank, S., \& Dachinger, P. (1974). Psychoanalytic reinterpretation of the effectiveness of systematic desensitization: Experimental data bearing on the role of merging fantasies. Journal of Abnormal Psychology, 83, 313-318.

Silverman, L. H., Levinson, P., Mendelsohn, E., Ungaro, R., \& Bronstein, A. A. (1975). A clinical application of subliminal psychodymanic activation: On the stimulation of symbiotic fantasies as an adjunct in the treatment of hospitalized schizophrenics. Journal of Nervous and Mental Disease, 161, 379-392.

Silverman, L. H., Martin, A., Ungaro, R., \& Mendelsohn, E. (1978). Effect of subliminal stimulation of symbiotic fantasies on behavior modification treatment of obesity. Journal of Consulting Psychology, 46, 432-441.

Silverman, L. H., \& Weinberger, J. (1985). Mommy and I are one: Implications for psychotherapy. American Psychologist, 40, 1296-1308.

Skinner, J., Molnar, M., \& Harper, R. (1989). Higher cerebral regulation of cardiovascular and respiratory functions. In M. Kryger, T. Roth, \& W. C. Dement (Eds.), Principles and practice of sleep medicine (pp. 231-251). Philadelphia: Saunders.

Steklis, H., \& Kling, A. (1985). Neurobiology of affiliative behavior in nonhuman primates. In M. Reite \& T. Field (Eds.), The psychobiology of attachment and separation (pp. 93-134). New York: Academic Press.

Stern, D. N. (1985). The interpersonal world of the infant: A view from psychoanalysis and developmental psychology. New York: Basic Books.

Stern, M. M. (1988). Repetition and trauma: Toward a teleonomic theory of psychoanalysis. Hillsdale, NJ: Analytic Press.

Van de Castle, R. L. (1994). Our dreaming mind. New York: Ballantine Books.

Vogel, G. W. (1993). Selective deprivation. In M. A. Carskadon (Ed.), Encyclopedia of sleep and dreaming (pp. 178-180). New York: Macmillan.

Winson, J. (1985). Brain and psyche: The biology of the unconscious. New York: Doubleday. 
Wu, J. C., \& Bunney, W. E. (1990). The biological basis of an antidepressant response to sleep deprivation and relapse: Review and hypothesis. American Journal of Psychiatry, 147, 14-21.

Zborowski, M. J., \& David, D. (1997, April). Depressive subtypes: An examination of object relations, dependency, narcissism, and dream content among anaclitic (dependent) and introjective (self-critical) young adults. Paper presented at the 68th Annual Convention of the Eastern Psychological Association, Washington, DC.

Zepelin, H. (1989). Mammalian sleep. In M. Kryger, T. Roth, \& W. C. Dement (Eds.), Principles and practice of sleep medicine (pp. 30-49). Philadelphia: Saunders. 